\title{
Safety of laparoscopic cholecystectomy in children using conventional instruments in a general teaching hospital by general surgeons: 14 years review
}

\author{
Shantabir Maharjan ${ }^{1}$, Jay Narayan Shah, ${ }^{1}$ Rajan Gurung, ${ }^{1}$ Shailedra Shah, ${ }^{1}$ Rajesh Mandal ${ }^{1}$, Reetu Baral ${ }^{2}$ \\ ${ }^{1}$ Department of Surgery \\ ${ }^{2}$ Department of Pathology
}

Patan Hospital, Patan Academy of Health Science, Lalitpur, Kathmandu, Nepal.

Correspondence: Dr. Shantabir Maharjan, Patan Hospital, PAHS, GPO Box 252, Kathmandu, Nepal.

Email: shantabm@yahoo.com

\begin{abstract}
Introduction: There is limited specialist facility and lack of data on gallstone and laparoscopic cholecystectomy (LC) in children locally and in the region. With one government children hospital in Nepal, specialist service is far from adequate. Utilizing existing facilities to provide service is the need. We analyzed 14 years data to look in to the safety of LC in children provided by general surgeons in a general teaching hospital with conventional LC instruments used for adults.

Methods: This descriptive review included children up to $14 \mathrm{y}$ of age who had cholecystectomy during 14 y period from 2002 to 2015. Data on sex, age; clinical and ultrasonography findings; risk factors for gallstone; types of surgeries; bile duct injury, would infection and in-hospital mortality were analyzed.

Results: There were 61 children, $0.8 \%$ of total 7469 cholecystectomy during 14 years study period. Average age was 9 years and females were 56 (84\%). Out of 58-attempted LC, 56 were completed successfully. All children had history of right upper quadrant pain. Two presented with acute calculous cholecystitis. We did not find associated risk factors for stones. There was no bile duct injury. One wound infection occurred in LC converted to open. In-hospital mortality was nil.

Conclusion: Cholelithiasis and cholecystectomy in children was low at $0.8 \%$ of total. With $3.4 \%$ conversion, no bile duct injury, no hospital mortality LC was safely provided by general surgeon in a general hospital using conventional facility.

Keywords: General surgeons; General teaching hospital; laparoscopic cholecystectomy in children; Safety profile.
\end{abstract}

\section{Introduction}

Prevalence of gallstones (GS) in children is low at 0.15 $2 \%$, one tenth of adults. ${ }^{1-3}$ Traditional practices of open cholecystectomy (OC) is increasingly replaced by laparoscopic cholecystectomy (LC). Literature is scarce on natural history and management of GS in children who have some specific risk factors for GS, like 'hemolytic disease (in up to 20-30\%), congenital anomalies, and use of Ceftriaxone'. ${ }^{4,5}$

Locally and in the region, we lack published data on GS and LC in children. With only one government children hospital in Nepal, need to plan to utilize existing facilities and human resource to serve the need of children. The LC for adult is widely practiced and can be expanded for children without added expense of pediatric LC equipments. 
This 14 years review aim to generate evidence on feasibility and safety of LC for children utilizing existing resources of general surgeons and conventional instruments used for adult LC in general hospital. Thus we aim that health planners and service providers can expand services for children and do not wait for ideal situation of having adequate 'specialists pediatric surgeon and facility'.

\section{Methods}

We reviewed 14 years' data from January 2001 to December 2015 on laparoscopic cholecystectomy in children at Patan Hospital, Patan Academy of Health Science (PAHS), Nepal. Patan Hospital policy defines age up to 14 years as children. Ethical approval was obtained from the institutional review committee of PAHS. Patient charts were retrieved based on information from operation room register, computer data base from pathology and discharge office. Data on age, gender, risk factors for gallstones (hemolytic anemia, total parenteral nutrition or use of Ceftriaxone), complications of GS (cholecystitis, cholangitis, pancreatitis), USG findings, types of surgery (LC, OC, LC converted to OC), surgical complications (bile leak, bile duct injury, wound infection), in hospital mortality and histopathology findings were recorded in pre-designed datasheet. Technique of LC in children is briefed in discussion section. Microsoft Excel was used for descriptive analysis.

\section{Results}

There were 67 children who had cholecystectomy during 14 years period from 2001 to 2015. Six children had cholecystectomy performed as completion surgery for choledochal cyst and were excluded. Remaining 61 cases $(0.8 \%$ of total 7469$)$ were reviewed. $56(84 \%)$ were females. Male female ratio was equal in young children. In older age group of 10 to 14 year, females were $88 \%$, (Table 1). Number of children with GS and LC increased over the years during the study period, (Table 2).

There were $56 \mathrm{LC}$ and five OC. Out of 58 attempted LC, $56(96.6 \%$ of 58$)$ were successfully completed and two were converted to $\mathrm{OC}$ due to difficult dissection. Two OC were for acute calculus cholecystitis and one was parents' choice. All children had history of right upper quadrant pain. Two intraoperative cholangiogram (IOC) performed for dilated common bile duct and difficult dissection were normal, (Table 3).

There was no pancreatitis, cholangitis or associated risk factor of GS. There was no bile duct injury during surgery. One wound infection occurred in LC converted to
OC. It healed after dressing. Histopathology reported no malignancy, (Table 3). In hospital mortality was nil.

Table 1. Age and sex distribution of Children $(n=61)$ who underwent cholecystectomy during 2001-15

$\begin{array}{ccccc}\text { Age } & \text { Total } & \begin{array}{c}\text { Female } \\ (\%)\end{array} & \begin{array}{c}\text { Male } \\ (\%)\end{array} \\ 2-14 \text { y } & 61 & \begin{array}{c}50 \\ (82)\end{array} & 11 & (8) \\ & & 5 & & \\ 2-9 y & 10 & (50) & 5 & (50) \\ 10-14 y & 51 & 45 & & \\ & & (88) & 6 & (12)\end{array}$

Table 2. Yearly distribution of cholecystectomy in children $(n=61)$ from year 2001-15

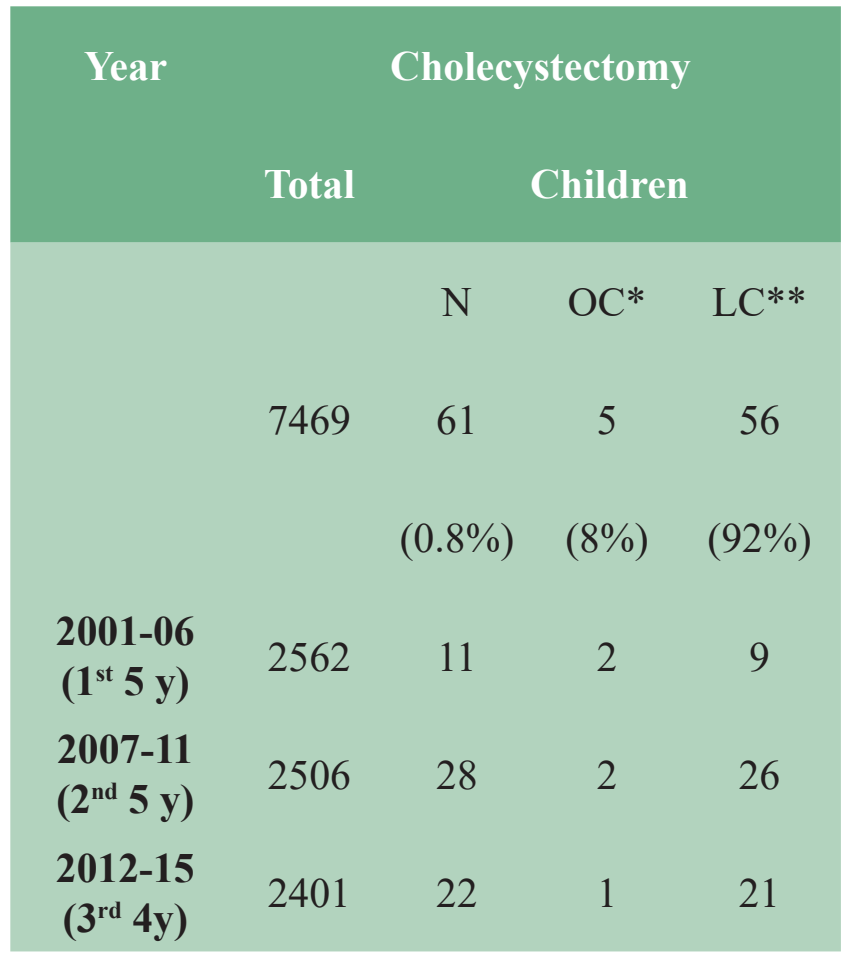

*Two elective LC converted to open due to adhesion, 2 were acute (LC was not attempted), 1 was parents choice.

**58 LC were attempted of which 56 (97\%) completed successfully. 
JSSN 2017; 20 (1)

Table 3. Clinicopathological features of children $(n=61)$ who had cholecystectomy during 2001-15

\begin{tabular}{|c|c|c|c|}
\hline & Clinicopathological features & $\mathbf{N}$ & $\%$ \\
\hline \multirow[t]{3}{*}{ Demographic features } & Male & 11 & 18 \\
\hline & Female & 50 & 82 \\
\hline & Average age in years (range $2 \mathrm{y}$ to $14 \mathrm{y}$ ) & 9 & \\
\hline \multirow[t]{2}{*}{ Presentation } & RUQ pain & 61 & 100 \\
\hline & RUQ pain, fever, leucocytosis (acute cholecystitis) & 2 & 3 \\
\hline \multirow[t]{2}{*}{ USG findings } & Single stone in GB & 15 & 25 \\
\hline & Multiple stone in GB & 46 & 75 \\
\hline Types gall bladder stones & Pigment & 34 & 56 \\
\hline \multirow[t]{2}{*}{ (as per operation notes) } & Mixed & 14 & 23 \\
\hline & Not mentioned & 13 & 21 \\
\hline \multirow[t]{4}{*}{ Surgery performed } & LC attempted & 58 & 92 \\
\hline & LC successful & 56 & 97 \\
\hline & $\mathrm{LC}$ to $\mathrm{OC}^{*}$ & 2 & 3 \\
\hline & $\mathrm{OC} * *$ & 5 & 8 \\
\hline Complication, & Bile duct injury & 0 & 0 \\
\hline \multirow[t]{2}{*}{ Outcome of surgery } & Wound infection $* * *$ & 1 & 3 \\
\hline & In hospital mortality & 0 & 0 \\
\hline \multirow[t]{2}{*}{ Histopathology } & Acute on chronic cholecystitis & 2 & 3 \\
\hline & Chronic cholecystitis & 59 & 97 \\
\hline
\end{tabular}

$\mathrm{RUQ}=$ right upper quadrant, $\mathrm{GB}=$ gall bladder, $\mathrm{USG}=$ ultrasonography, $\mathrm{LC}=$ laparoscopic cholecystectomy, $\mathrm{OC}=$ open cholecystectomy

* converted from LC to OC due to adhesion.

** out of five, two for to acute cholecystitis, one parents' choice, two LC to OC.

***occurred in one LC to OC, wound infection healed after dressing. 


\section{Discussion}

Our findings of low incidence of $0.8 \%$ (61 out of total 7469) cholecystectomy for GS in children is in line with published literatures that GS is uncommon in children than we observe in adults. ${ }^{1,2,4}$ Specific risk factors for stone formation, for example hemolytic disease, are reported in children unlike idiopathic stones in adults. ${ }^{4-6}$ We looked into the charts of children who had LC for the history of hemolytic anemia and laboratory reports of peripheral blood smear reports for possible hemolytic cause. There was no such association of presence of hemolytic disease and GS. At our hospital we do not routinely perform blood investigation to look for hemolytic disease unless there is suggestive clinical history of anemia, splenomegaly and blood transfusions. We also did not find predisposing factors of TPN, premature birth in this series. Spontaneous resolution of gallstones occurs in some children, for example, 'Ceftriaxone' induced cholelithiasis. ${ }^{4}$ We did not find such predisposing factors in our series.

From the operation notes, we observed that surgeons had documented visual inspection for types of stones, (Table 3 ). Pigment stones were most common (51\%), followed by mixed stones (21\%), similar to published reports. ${ }^{7}$ In this series, $28 \%$ of operation notes had no mention of type of stones. Better documentation is needed.

Incidentally found silent gallstones in children have low complication rate, except, when there is associated sickle cell disease, and spherocytosis. Hemolytic disorders have increased risk of developing pigment stones ranging from $4 \%$ in infancy to as high as $80 \%$ after the age of 30 years. These children frequently develop complications (biliary pain, acute cholecystitis, and choledocholithiasis) within 3 to 5 years of diagnosis of GS. ${ }^{8-10}$

Increased detection of stones due to wider use of USG combined with introduction and acceptance of minimally invasive surgery is one possibility of increase in LC. This was also seen in our series with increase in LC over the years, (Table 2). Biliary symptoms with no stones detected on conventional abdominal USG may benefit from endoscopic USG. ${ }^{11}$

Natural history of GS in children is not well documented. In younger children, both sexes are equally affected, but girls outnumber boys later at adolescence. We had similar observation, (Table 2). Asymptomatic stones are less common in children and cholecystectomy is often recommended in fit children with known risk factors. , $9,12-14^{-14}$ Our institutional policy is to generally operate on symptomatic cholelithiasis. Similar to published reports, we do not recommend routine intraoperative IOC because the incidence of common bile duct stones is low in children. ${ }^{15}$ Our hospital policy is to perform IOC in selected cases when there is altered liver function test or USG findings suggestive of common bile duct stones. ${ }^{16,17}$

Pathological evidence of chronic cholecystitis was reported in $59(97 \%$ of 61$)$ and two (3\%) had acute cholecystitis. This suggests most GS in children present with symptoms, as reported by other studies. ${ }^{13,14}$ All children in this series had history of RUQ pain and possible inflammation of gallbladder as reflected in histology findings of chronic cholecystitis. We had two (3\%) acute calculous cholecystitis presenting with RUQ pain, vomiting, fever, leucocytosis. Unlike in adults, expectant management of gallstone with history of RUQ pain is not recommended in children due to long life expectancy and associated pathology. Like in adults, day care and single incision laparoscopic surgery is become popular in children. ${ }^{18,19}$ This study provides baseline information on clinical profile of GS in children locally.

Similar to adults in our hospital practice, we used 4-ports technique for LC in children. Two $10 \mathrm{~mm}$ ports were at umbilicus and epigastrium; and two $5 \mathrm{~mm}$ ports on right upper abdomen. Low pressure pneumoperitoneum of $8-10 \mathrm{mmHg}$ was established by open technique via 10 $\mathrm{mm}$ umbilical port. This port was used for camera and to retrieve gall bladder specimen.

We do not routinely use retrieval bag due to cost. When required, for example, in suspected malignancy or gall bladder perforation, we use condom or cut 'thumb' of gloves. Depending on surgeon's preference either zero or 30 degree $10 \mathrm{~mm}$ diameter telescope was used through umbilical port. The $2^{\text {nd }} 10 \mathrm{~mm}$ port in epigastrium was the working port for dissection using $45 \mathrm{~cm}$ long $5 \mathrm{~mm}$ diameter curved forceps. Lateral $5 \mathrm{~mm}$ port was used for retraction and medial $5 \mathrm{~mm}$ port to maneuver gall bladder using $5 \mathrm{~mm}$ diameter atraumatic grasper. Double action 10 $\mathrm{mm}$ diameter clip applicator and titanium clips are used to secure cystic duct and artery, unlike our practice in adults of suture ligation ducts and artery without clips. ${ }^{20}$

At Patan hospital, we have been providing general anesthesia and general surgical services to children since the inception of hospital six decades ago. With only one government pediatric hospital in our country of 33 millions, the desirable specialist pediatric surgeons and expensive specialized laparoscopic instruments for children remains a distant dream. Situation may be similar in this region and 
in other resource constrain developing countries. Still, we should use available logistics and human resources so that the children should not be deprived of LC services.

Limitation of this study may be small sample size and retrospective data. Prospectively designed study with bigger sample size may better answer the questions of associated hemolytic disease in children with gallstones our context and complications of LC. We had wound infection in 3\% ( 1 of 61 ) in a case of LC to OC. As per hospital protocol we use single dose Cefazoline for preoperative antibiotic prophylaxis in gallstone surgery. However, this has been modified now to no prophylaxis in low risk LC (without cholangitis, pancreatitis, choledocholithiasis) after our earlier controlled trial and recent meta-analysis showing no benefit of prophylaxis..$^{21,22}$ There was no bile duct injury or in hospital mortality in this series. Laparoscopic cholecystectomy was safely provided to children using conventional instruments used for adults by general surgeon in general public hospital.

\section{Conclusion}

Cholelithiasis and cholecystectomy in children was uncommon at $0.8 \%$ of total cholecystectomy. With $3.4 \%$ conversion, no bile duct injury and zero in-hospital mortality, laparoscopic cholecystectomy was safely provided to symptomatic children by general surgeons using conventional laparoscopic instruments available for adults in a general public hospital.

\section{References}

1. E. J. Balaguer, MR Price, R. S. Burd. National Trends in the Utilization of Cholecystectomy in Children. J Surg Res. 2006;134:68-73. https://doi.org/10.1016/j.jss.2006.02.053 PMid:16650434

2. R. Ganesh, S. Muralinath, V.S. Sankaranarayanan, M. Sathiyasekaran. Prevalence of cholelithiasis in children: A hospital-based observation. Indian J Gastroenterol. 2005;24(2):85. PMid:15879668

3. Wesdorp, D. Bosman, A. de Graaff, D. Aronson, F. van der Blij, J. Taminiau. Clinical presentations and predisposing factors of cholelithiasis and sludge in children. J Pediatr Gastroenterol Nutr. 2000;31:411-7. https://doi.org/10.1097/00005176-200010000-00015 PMid:11045839
4. U. Poddar, "Gallstone disease in children. Indian Pediatr. 2010;47(11):945-53. https://doi.org/10.1007/s13312-010-0159-2

5. R. P. Punia, S. Garg, B. Bisht, U. Dalal, H. Mohan. Clinico-pathological spectrum of gallbladder disease in children. Acta Paediatr. 2010;99(10):1561-4. https://doi.org/10.1111/j.1651-2227.2010.01876.x PMid:20491704

6. D. Herzog, G. Bouchard. High rate of complicated idiopathic gallstone disease in paediatric patients of a North American tertiary care centre. World J Gastroenterol. 2008;14(10):1544-8. https://doi.org/10.3748/wjg.14.1544 PMid:18330945 PMCid:PMC2693749

7. M. D. Stringer, D. R. Taylor, R. D. Soloway. Gallstone composition: are children different? J Pediatr. 2003;142:43540. https://doi.org/10.1067/mpd.2003.159 PMid:12712064

8. M. N. Suell, T. I. Horton, M. K. Disi Iop, et al. Outcomes for children with gallbladder abnormalities and sickle cell disease. J Pediatr. 2004; 145:617-21. https://doi.org/10.1016/j.jpeds.2004.06.071 PMid:15520760

9. C. O. Bogue,A.J. Murphy, J. T. Gerstle, R. Moineddin,A. Daneman. Risk Factors, Complications, and Outcomes of Gallstones in Children: A Single-center Review. J Pediatr Gastroenterol Nutr. 2010;50(3):303-308. https://doi.org/10.1097/MPG.0b013e3181b99c72 PMid:20118803

10. I. M. Seleem, A. M. Al-Hashemy, S. S. Meshref. Mini-laparoscopic cholecystectomy in children under 10 years of age with sickle cell disease. ANZ J Surg. 2005;75(7):562-5. https://doi.org/10.1111/j.1445-2197.2005.03437.x PMid:15972048

11. L. P. Neff, G. Mishra, J. E. Fortunato, J. Laudadio, J. K. Petty. Microlithiasis, endoscopic ultrasound, and children: not just little gallstones in little adults. J Pediatr Surg. 2011;46(3):462-6. https://doi.org/10.1016/j.jpedsurg.2010.09.007 PMid:21376193

12. D. Miltenburg, R. Schaffer, T. Breslin, M. Brandt. Changing indications for pediatric 
cholecystectomy. Pediatrics. 2000;105:1250-53. https://doi.org/10.1542/peds.105.6.1250 PMid:10835065

13. D. J. Gowda, P. Agarwal, R. Bagdi, B. Subramanian, M. Kumar, M. Ramasundaram, B. Paramasamy, Z. S. Khanday. Laparoscopic cholecystectomy for cholelithiasis in children. J Indian Assoc Pediatr Surg. 2009;14(4):204-206. https://doi.org/10.4103/0971-9261.59602 PMid:20419021 PMCid:PMC2858882

14. C. Della Corte, D. Falchetti, G. Nebbia, M. Calacoci, M. Pastore, R. Francavilla, et al. Management of cholelithiasis in Italian children A national multicenter study. World J Gastroenterol. 2008;14:1383-8. https://doi.org/10.3748/wjg. 14.1383 PMid:18322952 PMCid:PMC2693686

15. G. Mattioli, A. Pini-Prato, M. Castagnetti, P. Gandullia, P. Toma, V. Jasonni. Is perioperative cholangiography necessary in children undergoing elective lapascopic cholecystectomy? Eur J Pediatr Surg. 2007;17:176-79. https://doi.org/10.1055/s-2007-965146 PMid:17638155

16. J.N. Shah, C. Shah. A Five Years Review Intra-Operative cholangiogram. J Nepal Health Res Counc. 2011;9(18):52-5. PMid:22929714

17. S. Pradhan, S. Shah, S. Maharjan, J.N. Shah. Presence of choledocholithiasis in patients undergoing cholecystectomy for mild biliary pancreatitis. Journal of Society of Surgeons of Nepal. 1014;17(1):11-15. https://doi.org/10.3126/jssn.v17i1.15175

18. K. Mendez, R. Sabater, E. Chinea, H. LugoVicente. Is there a safe advantage in performing outpatient laparoscopic cholecystectomy in children? J Pediatr Surg. 2007;42:1333-6. https://doi.org/10.1016/j.jpedsurg.2007.03.028 PMid:17706491

19. Y. H. Tam, K. H. Lee, J. D. Y. Sihoe, K. W. Chan, S. T. Cheung, K. K. Y Pang. Initial experience in children using conventional laparoscopic instruments in single-incision laparoscopic surgery. J Pediatr Surg. 2010;45:2381-5. https://doi.org/10.1016/j.jpedsurg.2010.08.036
PMid:21129550

20. JN Shah, SB Maharjan. Clipless laparoscopic cholecystectomy, a prospective observational study. Nepal Med Coll J 2010; 12(2): 69-71.) PMid:21222399

21. J.N. Shah, SB Maharjan, S Paudyal. Routine use of antibiotic prophylaxis in low-risk laparoscopic cholecystectomy is unnecessary: a randomized clinical trial. Asian J Surg. 2012;35:136-9. https://doi.org/10.1016/j.asjsur.2012.06.011 PMid:23063084

22. S. Pasquali, M. Boal, E. A. Griffths, D. Alderson and R. S. Vohra. Meta-analysis of perioperative antibiotics in patients undergoing laparoscopic cholecystectomy. Brit J Surg. 2016;103:27-34. ht tps://doi.org/10.1002/bj s. 9904 PMid:26331356 